\title{
Correction to: Clinical Effects of Syncope on Disease Severity and Adverse Outcomes in Children with Idiopathic and Heritable Pulmonary Arterial Hypertension
}

\author{
Shinichi Takatsuki ${ }^{1} \cdot$ Shun Yanai $^{1} \cdot$ Satoshi Ikehara ${ }^{1} \cdot$ Tomotaka Nakayama $^{1} \cdot$ Hiroyuki Matsuura $^{1}$
}

Published online: 17 December 2018

(c) Springer Science+Business Media, LLC, part of Springer Nature 2018

Correction to: Pediatric Cardiology

https://doi.org/10.1007/s00246-018-1996-3

The original version of this article unfortunately contained a mistake in the author name.

The co-author name should be Hiroyuki Matsuura instead of Horoyuki Matsuura.

The original article has been corrected.

The original article can be found online at https://doi.org/10.1007/ s00246-018-1996-3.

Shinichi Takatsuki

s-taka@med.toho-u.ac.jp

1 Department of Pediatrics, Toho University Omori Medical Center, 6-11-1 Omori-nishi, Ota-ku, Tokyo 1438541, Japan 